\title{
Perfil Intraempreendedor dos Líderes de Empresas de Base Tecnológica Associadas: um estudo de caso na Vertical de Segurança ACATE
}

\author{
Adriano DIAS ${ }^{1}$ \\ Ana Lúcia Ferraresi SCHMITZ2 \\ Antonio Marcos FELICIANO ${ }^{3}$ \\ Christine Bencciveni FRANZONI ${ }^{4}$ \\ Edis Mafra LAPOLLI ${ }^{5}$ \\ Waldoir Valentim GOMES JUNIOR
}

\author{
${ }^{1}$ Mestre em Engenharia e Gestão do Conhecimento - UFSC - adriano.dias@digitro.com.br \\ ${ }^{2}$ Doutora em Engenharia e Gestão do Conhecimento - UFSC - analucia.schmitz@ gmail.com \\ ${ }^{3}$ Doutor em Engenharia e Gestão do Conhecimento - UFSC - feliciano.antoniomarcos@gmail.com \\ ${ }^{4}$ Mestre em Engenharia e Gestão do Conhecimento - UFSC - christinefranzoni@ gmail.com \\ ${ }^{5}$ Doutora em Engenharia de Produção - UFSC - edismafra@ gmail.com \\ ${ }^{6}$ Mestre em Engenharia e Gestão do Conhecimento - UFSC - waldoir@gmail.com
}

\section{Recebido em: 15/05/2014 - Aprovado em: 30/06/2014 - Disponibilizado em: 30/07/2014}

\begin{abstract}
RESUMO: Embora seja considerada a relevância da estrutura e infraestrutura, bem como da proposição de valor do portfólio de cada empresa, é o perfil do capital humano dessas empresas, especialmente aquele envolvido na sua gestão, o fator essencial à sua perenidade, sobretudo no seu estágio inicial de vida, onde sobreviver é o objetivo maior. Identificar os sinais distintivos, bem como sua intensidade, nesta parte do capital intelectual das empresas consistiu o objetivo geral desta pesquisa. Partindo dos referenciais teóricos, o presente trabalho descreve os sinais distintivos (intra) empreendedores dos líderes das empresas de base tecnológica vinculadas à Associação Catarinense de Empresas de Tecnologia (ACATE), agrupadas em uma de suas verticais, qual seja, a Vertical de Segurança. Trata-se de uma pesquisa qualitativa cujos dados foram extraídos de descrição proveniente de entrevistas realizadas junto a um grupo de (intra) empreendedores, líderes de empresas de base tecnológica, e da aplicação de questionário a todos os gestores estratégicos das mesmas. O resultado da pesquisa evidencia que o perfil (intra) empreendedor muda em face ao estágio atual de vida de cada empresa, assim como demonstra a importância em se desenvolver os sinais que tipificam o aludido perfil para garantir a evolução das empresas.
\end{abstract}

Palavras - Chave: Perfil Intraempreendedor. Empresa de Base Tecnológica. Associativismo. Gestão do Conhecimento. Sinais Distintivos.

\section{Entrepreneur profile of the leaders of technological basis associated enterprises: a case study from "Segurança Vertical ACATE"}

\begin{abstract}
Although the relevance of structure and infrastructure is considered, as well as the value proposition of each company's portfolio, it is the profile of the human capital of these companies, especially those involved in its management, the key factor to their long-term survival, mainly in its early stage of life, when survival is the most important objective. The general objective of this research consisted in identifying the distinctive signs, as well as its intensity, in the intellectual capital of the companies. Starting from the theoretical references, this dissertation describes the distinctive entrepreneur signs of the leaders of technological-basis enterprises linked to Santa Catarina Technology Companies Association (ACATE), grouped into one of their axes, that is, the Security Axis. It is a qualitative research whose data were extracted from the description of interviews conducted with a group of entrepreneurs, leaders of technological-basis associated enterprises, and from the application of a questionnaire to all their strategic managers. The research result shows that the entrepreneur's profile changes according to the current stage of life of each company, and it also demonstrates the importance in developing the signs that typify the alluded profile to ensure the evolution of enterprises.
\end{abstract}

Keywords: Entrepreneur profile; Technology-based company; Associations; Knowledge management. 


\section{INTRODUÇÃO}

Até alcançarem seu ponto de equilíbrio, as empresas de base tecnológica tem seu foco voltado para a sobrevivência nos mercados onde estão se inserindo ou, já fazem parte. Nesse momento a conquista do reconhecimento de seu portfólio ocorre pela credibilidade que transmitem aos clientes conquistados, isso é, o portfólio é moldado na medida em que os contratos são consolidados. Normalmente, essas empresas têm um produto ou serviço que é ofertado a partir da rede de relacionamentos dos seus líderes que, quando contratado, é personalizado para aquele cliente. $\mathrm{O}$ foco naquele momento é resolver o problema do cliente objetivando satisfazer suas necessidades para obter uma referência. No entanto, por mais inovador que seja o produto ou serviço, há, nos clientes em prospecção, natural desconfiança que precisa ser vencida, ocorrendo somente quando esse se satisfaz com o que foi ofertado. Os clientes são conquistados a partir da capacidade empreendedora da empresa, isto é, a capacidade de entrega de valor para os clientes. Este é um dos momentos onde se distingue os empreendedores dos não empreendedores e onde podem ser identificadas as características que lhes conferem um perfil adequado para sobreviver profissional e economicamente. Após os primeiros clientes, a empresa cresce até alcançar seu ponto de equilíbrio, isto é, o ponto onde ela consegue pagar suas contas.
Esse é um momento importante onde se identificam outras características que informam tendências de crescimento ou estagnação.

Normalmente, as empresas, quando conseguem atingir seu ponto de equilíbrio o fazem definindo o tamanho da capacidade de realização de seus líderes. Na medida em que outros patamares são alcançados, outras características que compõem o perfil empreendedor ficam mais aparentes e precisam ser trabalhadas pela necessidade que o empreendedor passa a possuir em explorálas.

O cenário apresentado demonstra que, durante todo o ciclo de vida das empresas, o perfil empreendedor é um dos mais importantes fatores para sua sobrevivência e crescimento, e este é o objeto desta investigação, onde o trabalho foi realizado junto aos líderes das empresas de base tecnológica associadas à Associação Catarinense de Empresas de Tecnologia (ACATE), vinculadas à Vertical de Segurança desta Associação.

\section{REFERÊNCIAL TEÓRICO}

O referencial teórico trata dos cinco sinais distintivos dos empreendedores, que são: polivalência, velocidade, visão, capacidade de realização e capacidade de relacionamento interpessoal. 


\section{Sinais Distintivos dos Empreendedores}

$\mathrm{Na}$ perspectiva aqui adotada, o perfil empreendedor é percebido por um conjunto de sinais distintivos, descritos por Bueno e Lapolli (2001), que são: velocidade, polivalência, visão, capacidade de realização e capacidade de relacionamento interpessoal, e que estão aqui destacados.

- Velocidade: sinal que tem como predeterminação, a prontidão, a atenção, o planejamento, o espírito de liderança e a capacidade de, em situações emergentes, tomar decisões urgentes. A velocidade exige um raciocínio rápido sobre o enfrentamento de problemas e uma consequente capacidade de expressar bem as idéias de forma oral ou escrita;

- Polivalência: revela aptidões internas tais como a fácil adaptação a grupos e ambientes, flexibilidade nas idéias e ações e capacidade de desenvolver várias tarefas de diferentes áreas simultaneamente;

- Visão: constitui-se sob a formação e a experiência em situações reais e em teorias que proporcionam, geralmente, capacidade de compreensão, análise, avaliação e ação sobre as situações da vida e do trabalho, tendo por resultado a visualização dos cenários pretendidos e do caminho para alcança-los;

- Capacidade de Realização: geralmente

é percebida como consequência do planejamento preciso dos empreendimentos a partir de conhecimentos, análises, estudos de erros e avaliações acerca dos caminhos tortuosos a serem seguidos por eventualidades e possibilidades de retomada das rotas adequadas. É marcante neste sinal distintivo, a condição de sempre superar obstáculos para nunca deixar de realizar as atividades necessárias;

\section{- Capacidade de Relacionamento}

Interpessoal: define-se como a aptidão de equilíbrio emocional próprio e de interferência no equilíbrio emocional dos outros e das organizações. Capacidade de harmonizar grupos e de persuadir. Compreensão acerca das ações e reações pessoais e dos outros diante de situações difíceis, concorrências ou rivalidades. Predisposição para orientação psicológica própria e de grupos.

Para Bueno e Lapolli (2001) os sinais distintivos do empreendedor são indissociáveis e perpassam entre si, de forma a estabelecer uma conexão ativa simultânea entre todos os sinais durante a tomada de decisões e seus desdobramentos em ações. Convém destacar que em empreendimentos desenvolvidos, geralmente encontra-se, um, dois ou três sinais mais acentuados nos empreendedores, o que, conforme os autores, não descaracteriza o empreendedor.

\section{Empresa de Base Tecnológica}

Considerando o contexto da pesquisa, e as observações obtidas durante as entrevistas não estruturadas realizadas, um fundamento que caracteriza a empresa de base tecnológica é o de Albernathy e Utterback 
(1978), segundo os quais são empresas que possuem processos flexíveis de produção que lhes permite manter um padrão de inovação fluído, onde o capital humano é, em regra, altamente qualificado e possuidor dos sinais distintivos do perfil (intra) empreendedor. Nestas empresas, não existe controle organizacional formal. Para os autores, as empresas de base tecnológica geralmente se formam e se desenvolvem ao redor de pólos de tecnologia e de Universidades.

Para o primeiro, Castells (1989), as empresas de base tecnológica utilizam como principal matéria prima, o conhecimento. Quando empresas desta natureza adquirem maior porte, normalmente perdem parte de seu capital humano intraempreendedor que inicia seu próprio negócio, donde se depreende que o principal nascedouro de empresas de base tecnológica, além das Universidades, são as próprias empresas de base tecnológica.

Cândido e Dias (1998) afirmam que tais empresas possuem uma estrutura organizacional leve e informal onde os colaboradores são polivalentes, donde se conclui que não existe distância entre a alta direção e a linha de produção. A gestão destas empresas é exercida pelo próprio proprietário e a mão de obra familiar é bastante aproveitada, especialmente no início do seu ciclo de vida.

Autores como Castells (1989), Albernathy e Utterback (1978) asseveram que as empresas de base tecnológica possuem como principal capital, o capital humano qualificado e intraempreendedor, com foco quase que excluso na satisfação dos seus clientes, resolvendo-lhes os problemas para os quais foram chamados à resolver. A maior parte da sua matéria é o conhecimento, especialmente o novo conhecimento.

\section{Associativismo}

O associativismo é uma das formas de organizar grupos de interesse que possam sustentar seus princípios na conjugação de suas potencialidades num ambiente colaborativo. A integração social pode ser percebida no estudo de Silveira e Silva (2011) que aborda a importância histórica do associativismo, na perspectiva de uma visão histórico cultural. Entende que a formação da empresa na sociedade do futuro passa pelo pensamento e avaliação dos valores sociais que estão envolvidos os quais convivem cotidianamente. O associativismo é o resultado do acompanhamento social.

$\mathrm{Na}$ perspectiva do associativismo de empresas em ambientes competitivos, uma de suas principais facetas é que a competitividade poder estar num ambiente colaborativo, como o proposto por Amato Neto (2000), ao refletir sobre redes de colaboração na formação de aglomerados de empresas visando o alcance da eficácia da coletividade. Neste sentido, Caniels e Romijn (2003) entendem que a interação e relacionamento entre determinadas empresas 
correlatas e/ou integrantes são chamadas clusters.

Porter (1998, p. 81) define cluster como sendo:

[...] concentrações geográficas de empresas e instituições interconectadas numa área de atuação particular. Incluem um conjunto de empresas e outras entidades ligadas que são importantes para a competição. Eles incluem, por exemplo, fornecedores de insumos especializados, tal como componentes, máquinas, serviços e provedores de infra-estruturas especializadas. Clusters, frequentemente, se estendem na cadeia para incluir canais de comercialização e mesmo compradores, ou produtores de bens complementares, atingindo algumas vezes empresas relacionadas por qualificação da mão-de-obra, tecnologias, ou insumos comuns. Finalmente, muitos clusters incluem instituições governamentais e de outra natureza, tais como Universidades, instituições de controle de qualidade, instituições de pesquisa e geração de idéias, especializadas em qualificação profissional, e associações patronais, que provêem treinamentos especializados, educação, informações, pesquisa, e suporte técnico.

No estudo apresentado por Cezarino e Campomar (2006), verifica-se o valor de um cluster ou um Arranjo Produtivo Local (APL) como forma de viabilizar ações que possibilitem combater e criar melhores condições para as organizações frente a globalização, principalmente no desenvolvimento de vantagem competitiva.

Para Santos e Oliveira Neto (2011), a inclusão de uma empresa em um APL pode levá-la a obter a externalidades econômicas (facilidade de acesso à matéria-prima e mão de obra qualificada dentre outros) e, ao mesmo tempo, oportuniza ao arranjo potencializar sua competitividade.

\section{Gestão do Conhecimento}

A abordagem conceitual que segue procura demonstrar a importância da gestão do conhecimento como um ativo intangível fundamental para as organizações e para os empreendedores que objetivam manter, ampliar e perenizar-se nos mercados. Além desse aspecto, quando articulados, os conhecimentos tácito e explícito oferecem relevantes diferenciais competitivos, sobretudo quando esses conhecimentos têm origem em fontes confiáveis e próximas, como organizações parceiras. A gestão do conhecimento oferece elementos que perpassam a sistematização do conhecimento, chegando ao seu uso estratégico, em movimento espiral, de uso e reuso, com a consequente produção de mais conhecimento.

Para Fialho et al (2007, p. 114), a gestão do conhecimento consiste no “[...] gerenciamento inteligente, ordenado, sistematizado e eficaz de tudo aquilo que a empresa sabe e agrega de valor ao negócio”. Angeloni (2008) define a gestão do conhecimento organizacional como o conjunto de processos que governa a aquisição, a criação, o compartilhamento, o armazenamento e a utilização de conheci-mento no âmbito das organizações. Por fim, Gudas (2009) compreende que a gestão do conhecimento tem por objetivo, a criação de um contexto organizacional visando efetivar a geração, o armazenamento, a disseminação e o uso do conhecimento como fator essencial à 
competitividade organizacional em um ambiente em constante mudança.

\section{CAMINHO METODOLÓGICO}

Trata-se de investigação teóricoempírica, com pesquisa de campo realizada com as empresas de base tecnológica associadas a Vertical de Segurança da ACATE (Associação Catarinense de Empresas de Tecnologia). Para o levantamento dos dados realizou-se a aplicação de questionário online, com trinta questões objetivas, enviadas por meio do GoogleDoc, em que todas as empresas participaram. Utilizou-se ainda o método da entrevista semi-estruturada, com duração média de 90 minutos, gravadas eletronicamente e posteriormente transcritas, à líderes das empresas de base tecnológica associadas à Vertical de Segurança da ACATE. A partir dos dados coletados, foi feita a análise do conteúdo das entrevistas e compilação dos resultados do questionário, caracterizando a pesquisa como qualitativa dos tipos genérica e estudo de caso. Cabe destacar que no momento da pesquisa, a Vertical de Segurança continha dezessete empresa, dessas, todas responderam ao questionário, e quatro emrpesas participaram da entrevista.

Ainda utilizou-se revisão sistemática para nortear os pesquisadores as fontes e contribuições científicas, onde o foco recaiu nos termos: empreendedorismo, gestão do conhecimento e empresas de base tecnológica, feita a partir da base de dados Scopus ${ }^{1}$, fez-se a tradução idiomática a fim de aprofundar e reduzir as perdas de registros relevantes ao assunto. Adicionalmente foi realizada pesquisa bibliográfica sobre os termos que fundamentam a pesquisaonde utilizou-se livros, teses, dissertações e outros materiais.

\section{RESULTADO DA PESQUISA DE CAMPO}

O estudo de caso foi realizado na ACATE, fundada em 01/04/1986, com a denominação de Associação Catarinense de Empresas de Telemática e Eletrônica, teve sua atuação iniciada com abrangência na região da Grande Florianópolis. Com o passar do tempo passou a atuar na representação institucional de associados de todas as regiões do Estado de Santa Catarina. Mantém vigorosa estrutura de agrupamento de empresas de base tecnológica organizada segundo diversos segmentos da economia, quais sejam: Telecom; Saúde; Têxtil; Segurança; Energia; Educação; Games; Agronegócios; Governo; e Sustentabilidade. A Vertical de Segurança congrega 17 empresas de base tecnológica que ofertam bens e serviços para os nichos de segurança pública, segurança privada patrimonial, segurança de acesso físico, e segurança da informação. Como resultado da pesquisa de campo

\footnotetext{
${ }^{1}$ http://www.scopus.com
} 
obteve-se, a partir das questões objetivas, a seguinte pontuação para os sinais distintivos:

Figura 1 - Pontuação dos Sinais Distintivos Obtidos por meio de Questionário

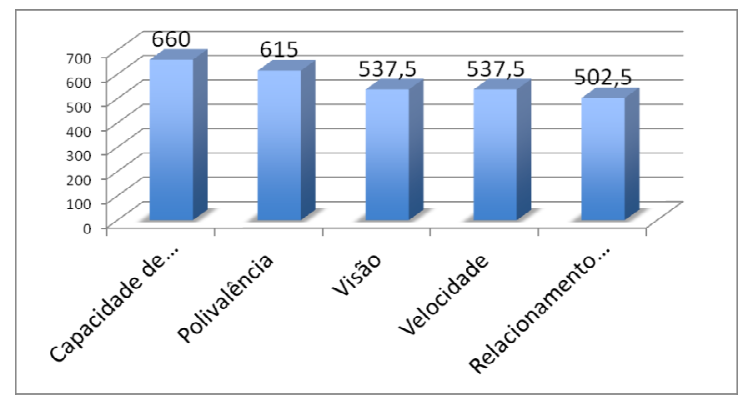

Fonte: autores, 2013.

A partir da tabulação dos questionários respondidos, foram obtidos os seguintes scores para cada sinal distintivo: a) Capacidade de Realização com 660 pontos; b) Polivalência com 615 pontos; c) Visão com 537,5 pontos; d) Velocidade com 537,5 pontos; Relacionamento Interpessoal com 502,5 pontos. A adesão das respostas foi de, aproximadamente, 70\%. Os argumentos escutados para explicar os atrasos nas respostas e as não participações, disseram respeito às atividades intensas do dia a dia dos líderes. Paralelamente à aplicação dos questionários, foram realizadas entrevista com líderes das empresas de base tecnológica, cujos resultados são apresentados na figura 2 :
Figura 2 - Pontuação dos Sinais Distintitvos Obtidos por meio de Entrevistas

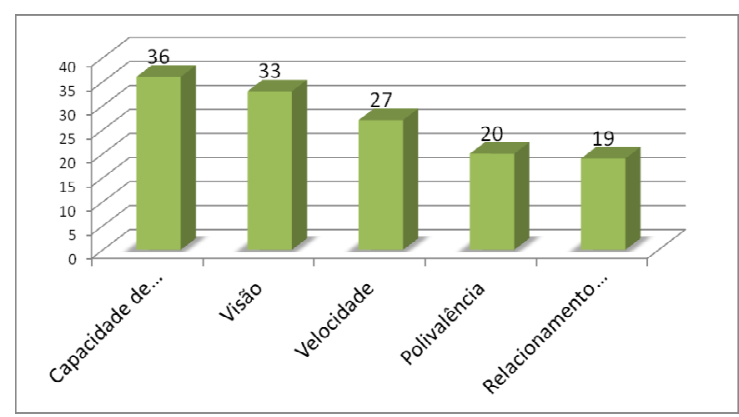

Fonte: autores, 2013.

As entrevistas não estruturadas resultaram nos seguintes scores, após processo interpretativo de análise baseada em conteúdo e nas observações dos pesquisadores durante a realização das entrevistas: a) Capacidade de Realização com 36 pontos; b) Visão com 33 pontos; c) Velocidade com 27 pontos; d) Polivalência com 20 pontos; e e) Relacionamento Interpessoal com 19 pontos. Os valores são, naturalmente, menores em face ao número de questões e de entrevistados. $\mathrm{O}$ levantamento de dados foi suficiente para permitir sua análise à luz das fundamentações teóricas já explicitadas anteriormente.

\section{ANÁLISE DOS DADOS}

Os dois métodos utilizados permitiram observar a diferença entre o dizer - questionário (GoogleDocs) e o fazer - entrevista. Assim, realizou-se uma análise para cada uma das quatro empresas investigadas.

O sinal da polivalência, no questionário objetivo construído para coletar a autopercepção dos entrevistados, encontra-se 
como segundo mais desenvolvido, enquanto, na coleta baseada na ação encontra-se como o quarto mais desenvolvido. Os sinais da visão e da velocidade aparecem empatados em terceiro lugar nos resultados tabulados a partir da percepção dos entrevistados, enquanto nas entrevistas não estruturadas a visão aparece como bem desenvolvida, seguida da velocidade. O sinal distintivo do relacionamento interpessoal figura como o menos desenvolvido em ambas as coletas, contudo, nas questões objetivas ele aparece distante $23,86 \%$ do sinal mais desenvolvido, enquanto nas questões não estruturadas ele aparece distante $47,22 \%$ estando, portanto, bem menos desenvolvido.

Em termos relativos, os sinais distintivos do perfil (intra) empreendedor são mais heterogêneos nas questões orientadas para a ação do que nas questões objetivas onde aparecem de forma mais homogênea. Os sinais da capacidade de realização e do relacionamento interpessoal indicam unicidade das interpretações, diferenciando-se apenas na distância entre um e outro.

\begin{tabular}{|c|c|c|c|c|c|}
\hline Levantamento & CR & VI & VE & PO & RI \\
\hline $\begin{array}{c}\text { Questionário } \\
\text { Objetivo }\end{array}$ & 100,00 & 81,43 & 81,43 & 93,18 & 76,14 \\
\hline $\begin{array}{c}\text { Entrevista Não } \\
\text { Estruturada }\end{array}$ & 100,00 & 91,67 & 75,00 & 55,56 & 52,78 \\
\hline Total & 200,00 & 173,10 & 156,43 & 148,74 & 128,92 \\
\hline Média & 100,00 & 86,55 & 78,22 & 74,37 & 64,46 \\
\hline
\end{tabular}

Pelo fato de não ser objeto de estudos, não foram obtidos dados que permitissem identificar o estágio do ciclo de vida das empresas para que se pudesse realizar análise circunstanciada do perfil frente ao estágio em que se encontram as empresas. Isso pode ser motivo de nova pesquisa que permita verificar se o perfil empreendedor atual de cada líder está em consonância com as necessidades da sua empresa pelo estágio em que se encontra.

Se utilizarmos o critério segundo o qual o maior score seja a nota máxima, dez, e os demais são obtidos por regra de três simples, chegamos a um resultado que, pela média, alcança a de desenvolvimento de cada sinal. O Quadro 1 demonstra esta análise e Figura 3 apresenta-a na forma de gráfico.

Quadro 1 - Quadro Demonstrativo dos Sinais Distintivos apresentados na Aplicação dos Métodos de Pesquisa - Questionário e Entrevista

Fonte: autores, 2013

Ficam assim, definidos os sinais distintivos mais desenvolvidos: a) Capacidade de Realização (CR); b) Visão (VI); c) Velocidade (VE); d) Polivalência (PO); e Relacionamento Interpessoal (RI). Destoam a capacidade de realização, 13,45 pontos percentuais acima do segundo colocado, e o relacionamento interpessoal, 9,91 pontos percentuais abaixo do penúltimo sinal distintivo menos desenvolvido.

Ao contrário do que pode se concluir à luz de uma ou de outra forma de coleta de dados, os sinais distintivos da velocidade e da polivalência são os que mais próximos se encontram, distantes somente 3,85 pontos 
percentuais um do outro. Todos sinais distintivos do perfil (intra) empreendedor estão presentes, como não poderia deixar de ser, contudo, seu desenvolvimento merece reflexão se tidos como condicionantes para a sobrevivência e crescimento das empresas de base tecnológica pesquisadas.

Figura 3 - Consolidação dos Dados Levantados

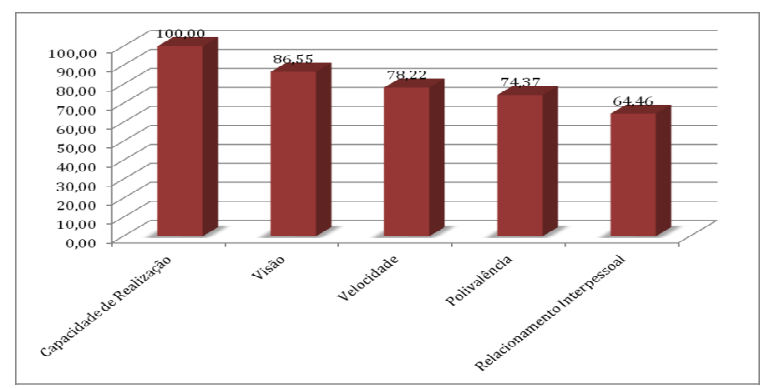

Fonte: autores, 2013.

\section{CONSIDERAÇÕES FINAIS}

A presente investigação partiu cômoda seguinte pergunta: Qual o perfil (intra) empreendedor dos líderes das empresas de base tecnológica associadas da ACATE, e inscritas na Vertical de Segurança?

A partir dos fundamentos teóricos e da consolidação do levantamento de dados por duas perspectivas, uma objetiva e outra subjetiva, as análises apontaram que os resultados obtidos evidenciam que os líderes das empresas pesquisadas possuem desenvolvidos os sinais distintivos da capacidade de realização e da visão. Os sinais da velocidade e da polivalência encontram-se em estágio que requer algum aprimoramento, enquanto o sinal do relacionamento interpessoal exige considerável carga de desenvolvimento. Este sinal tem sua relevância acentuada na medida em que as empresas vão evoluindo em seus estágios. A partir do estágio de crescimento este sinal vai ganhando importância até alcançar seu ápice no estágio de renovação, sendo que ocorre o inverso com o sinal da capacidade de realização.

$\mathrm{Na}$ medida em que as empresas crescem, seus líderes tendem a sair da operação, subindo os degraus tático e estratégico e, sempre que há mudança de degrau, a importância dos sinais distintivos sofre modificações. Nas fases da maturidade e da renovação, por exemplo, o sinal do relacionamento interpessoal ganha importância significativa, pois, comumente, os líderes já não se encontram mais na operação ou no nível tático, e sua capacidade de persuasão, influência e motivação, ganham relevância no contexto corporativo.

Com a capacidade de realização ocorre o inverso, pois na medida em que deixa de "por a mão na massa", para atender a outras necessidades que afloram, o líder não precisa mais ter, tão desenvolvido, este sinal distintivo. O mesmo ocorre com a polivalência de tal forma que, na medida em que a empresa evolui e, consequentemente, se estrutura e organiza, menos polivalente necessitam ser os líderes e fundadores. Quanto aos sinais da visão e da velocidade, o grau de exigência destes sinais se mantém durante todo o ciclo de vida da empresa pois eles representam 
mais proximamente a sua capacidade empreendedora que nunca deve mudar.

Embora pouco utilizados nesta pesquisa, os fundamentos da gestão do conhecimento perpassam os fundamentos do (intra) empreendedorismo, especialmente no que diz respeito à capacidade de inovação das empresas. Tais fundamentos foram suficientes para demonstrar, na cadeia de valor do conhecimento, onde se situam as pesquisas do empreendedorismo, especialmente para as empresas orientadas para inovação como é o caso das micro, pequenas e médias empresas (MPME) de base tecnológica como as que foram pesquisadas.

Esta pesquisa demonstra a relevância em situar os sinais distintivos do perfil empreendedor no processo de inovação das empresas, principal fator motivador concreto da sua sobrevivência e crescimento. No

\section{REFERÊNCIAS BIBLIOGRÁFICAS}

ABERNATHY, W., UTTERBACK, J. Patterns of industrial innovation. Technology Review. v. 80 n.7. p. 40-47. 1978.

AMATO NETO, J. Redes de cooperação produtiva e clusters regionais oportunidades para as pequenas e médias empresas. São Paulo: Atlas/Fundação Vanzolini, 2000.

ANGELONI, M. T. (Org.). Organizações do conhecimento: infraestrutura, pessoas, tecnologias. 2. ed. São Paulo: Saraiva, 2008.

BARBIERI, Geraldo. Fluxo de Caixa modelo para bancos múltiplos. Tese de doutorado. São Paulo: FEA/USP, 1995. contexto desta pesquisa, o mais importante é saber que, por meio de técnicas baseadas em jogos e vivências empreendedoras, é possível desenvolver o perfil empreendedor dos líderes empresariais.

Apesar de orbitarem no entorno de uma instituição representativa (ACATE) as empresas não potencializam, do ponto da gestão do conhecimento, aspectos como o uso e o compartilhamento do conhecimento. Também foi possível observar que, apesar de aderirem ao associativismo, desenvolvem seus projetos quase que individualmente, deixando de explorar as capacidades e o potencial que o conjunto de empresas poderia oferecer à competitividade individual e coletiva.

BUENO, José Lucas Pedreira; LAPOLLI, Édis Mafra. Vivência empreendedoras: empreendedorismo tecnológico na educação. Florianópolis: UFSC, 2001.

CÂNDIDO, G. A.; DIAS, S. T. A. A organização das pequenas e médias empresas: $O$ que revelam os estudos brasileiros. Relatório de Pesquisa CNPQ/UFPB/PIBIC. João Pessoa: Ed. Universitária, 1998.

CANIELS; M.; ROMIJN, H. SME clusters, acquisition of technological capabilities and development: concepts, practices and police lessons. Journal of Industry, Competition and Trade, v. 3, n. 3, p. 187-210; Sept. 2003.

CASTELLS, M. The Informational City: Information Technology, Economic Restructuring, and the Urban Regional 
Process. Oxford, UK; Cambridge, MA: Blackwell, 1989.

CEZARINO, L. O.; CAMPOMAR, M. C. Vantagem competitiva para micro, pequenas e médias empresas: clusters e APL's. $E \& G$. Economia e Gestão, v. 06, p. 143-158, 2006.

FIALHO, F. A. P. et al. Empreendedorismo na Era do Conhecimento. São Paulo: Visual Books, 2007.

GUDAS, S. Enterprise knowledge modelling: Domains and aspects. Technological and Economic Development of Economy. v.15, n 2, pp. 281-293, 2009.

PORTER, M. Clusters and the New Economics of Competition. Harvard Business Review. p. 77-90, Nov./Dec. 1998.

SANTOS, J. P.; OLIVEIRA NETO, G. C. Arranjo Produtivo Local (APL) Uma Visão Moderna do Associativismo a Difícil Tarefa de Unir o Setor. In: VII CNEG - Congresso Nacional de Excelência em Gestão, 2011.

SILVEIRA, M. S. R.; SILVA, R. P.

Associativismo e Cooperativismo: uma análise histórico-cultural. Revista Autor.

Disponível em:

$<$ http://www.revistaautor.com/portal/index.ph p?option=com_content $\&$ view $=$ article $\& i d=70$ 1:associativismo-e-cooperativismo-umaanalise-historicocultural\&catid=100:polca\&Itemid =47>, acesso em 01/09/2012. 